\title{
Concepts and Mechanisms: Crossing Host Barriers
}

\author{
Kelly S. Doran ${ }^{1,2}$, Anirban Banerjee ${ }^{1}$, Olivier Disson ${ }^{3,4}$, and Marc Lecuit ${ }^{3,4,5}$ \\ ${ }^{1}$ Department of Biology and Center for Microbial Sciences, San Diego State University, San Diego, \\ California 92182 \\ ${ }^{2}$ Department of Pediatrics, University of California, San Diego, La Jolla, California 92123 \\ ${ }^{3}$ Institut Pasteur, Biology of Infection Unit, French National Reference Center, and WHO Collaborating \\ Center for Listeria, Paris 75015, France \\ ${ }^{4}$ INSERM, U1117 Paris, France \\ ${ }^{5}$ Université Paris Descartes, Sorbonne Paris Cité, Institut Imagine, Centre d'Infectiologie Necker-Pasteur, \\ Hôpital Universitaire Necker-Enfants Malades, Paris 75015, France \\ Correspondence: kdoran@mail.sdsu.edu; marc.lecuit@pasteur.fr
}

\begin{abstract}
The human body is bordered by the skin and mucosa, which are the cellular barriers that define the frontier between the internal milieu and the external nonsterile environment. Additional cellular barriers, such as the placental and the blood-brain barriers, define protected niches within the host. In addition to their physiological roles, these host barriers provide both physical and immune defense against microbial infection. Yet, many pathogens have evolved elaborated mechanisms to target this line of defense, resulting in a microbial invasion of cells constitutive of host barriers, disruption of barrier integrity, and systemic dissemination and invasion of deeper tissues. Here we review representative examples of microbial interactions with human barriers, including the intestinal, placental, and bloodbrain barriers, and discuss how these microbes adhere to, invade, breach, or compromise these barriers.
\end{abstract}

\section{INVASIVE PATHOGENS AND HOST BARRIER}

critical event in systemic infection is the
multiple host barriers (Fig. 1). It can schemat-
ically occur according to two nonexclusive
scenarios: (i) the barrier function of a tissue
can be compromised either by physical means
(wound, catheter, surgery, arthropod bite) or in
the context of a host condition that disrupts
the integrity of tissues (inflammation, dysfunc-
tion of a host gene product implicated in bar- rier function), and this barrier damage allows microbial invasion; (ii) barrier(s) can also be crossed actively, via the direct action of microbial gene products that mediates microbial adhesion to and translocation across cells constitutive of host barriers.

\section{ENTEROPATHOGENS AND THE INTESTINAL BARRIER}

The skin and mucosa form the barriers that separate the host from its external nonsterile

Editors: Pascale Cossart and Stanley Maloy

Additional Perspectives on Bacterial Pathogenesis available at www.perspectivesinmedicine.org

Copyright (C) 2013 Cold Spring Harbor Laboratory Press; all rights reserved; doi: 10.1101/cshperspect.a010090

Cite this article as Cold Spring Harb Perspect Med 2013;3:a010090 
K.S. Doran et al.

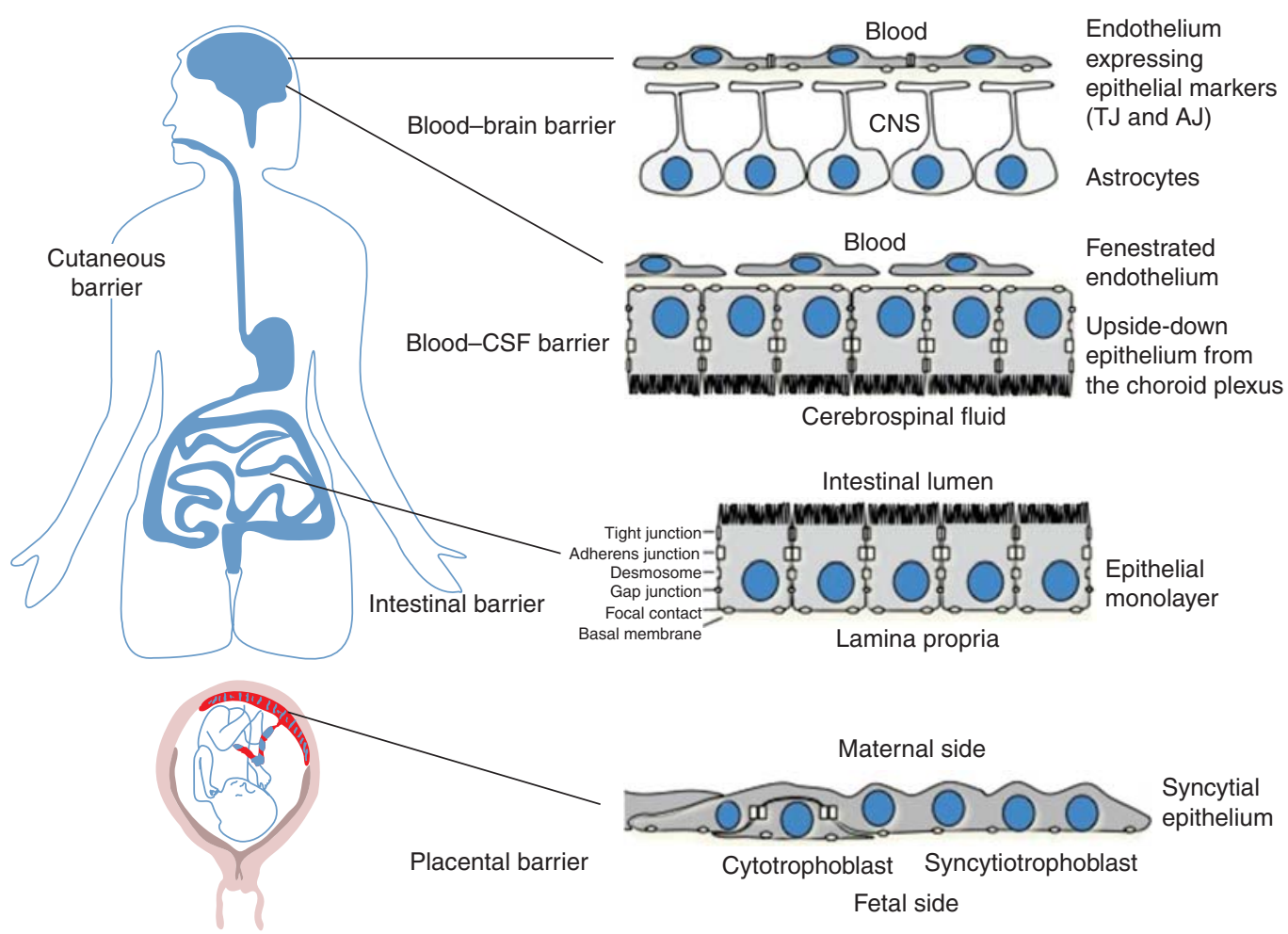

Figure 1. Example of host barriers. From top to bottom: The blood-brain barrier is made by brain endothelial cells that express tight junctions. The blood-CSF barrier is constituted by a monolayer of epithelial cells from the choroid plexus, which separates the blood located in a fenestrated endothelium from the cerebrospinal fluid. The intestinal barrier is a mucosal barrier made by a monolayer of epithelial cells. The placental barrier is constituted by both syncytial trophoblastic cells and mononuclear cytotrophoblasts.

environment. The intestinal barrier is made of a monolayer of polarized epithelial cells called enterocytes. Tight junctions (TJs) and adherens junctions (AJs) hold together enterocytes. TJs are the most apical structures and are made of transmembrane proteins (occludins, claudins, junction adhesion molecules [JAMs], and the coxsackievirus and adenovirus receptor [CAR]), connected to intracellular proteins (such as ZO$1,-2,-3$, MAGUK, and PAR family proteins). TJs prevent paracellular diffusion of molecules or luminal microorganisms (Anderson et al. 2004). AJs are required for the integrity of TJs and are located directly below them (Harris and Tepass 2010). They are made of E-cadherin, which is connected to the actin cytoskeleton. AJs and TJs are located at the apical and luminal side of enterocytes. Their basolateral side seats on a basement membrane made of extracellular matrix proteins, which separate them from the lamina propria, that contains connective tissue, stromal cells, blood and lymphatic capillaries, and cellular effectors of the immune system, such as lymphocytes, dendritic cells, or resident macrophages, some of which are in direct contact with enterocytes and the intestinal lumen via extending dendrites (Rescigno and Di Sabatino 2009).

The intestinal epithelium apical surface delineates the interface between the host and the intestinal lumen. The intestinal barrier is in continuous contact and crosstalk with up to $10^{14}$ microorganisms, which constitute the intestinal microbiota. It represents a major potential portal entry for microbes into the host. Microbial pathogens have evolved specific capacities to adhere to, invade, or disrupt the intestinal barrier (Sousa et al. 2005; Guttman and Finlay 
2009; Yoshida et al. 2011). These pathogens have to counteract host defenses and competition from the resident microflora in the gut. $\mathrm{Mi}$ crobes can cross epithelial barriers by disrupting intercellular junctions or by interacting with epithelial cell receptors, leading to the traversal in a transcellular or paracellular route. Pathogens may also take advantage of the luminal sampling property of host cells to get access to the lamina propria.

\section{Disruption of Tight Junctions by Enteropathogens}

Intestinal pathogens may adhere to the apical surface of enterocytes, remain extracellular, and modify the barrier properties of the epithelium. This event can lead to local invasion of the lamina propria. Enteropathogenic and enterohemorrhagic E. coli (EPEC and EHEC) are diarrheagenic bacteria (Wong et al. 2011) that affect TJs (occluding and ZO-1) through type-III secretion system (TTSS) effectors EspF, Map, and EspG (Dean and Kenny 2004; Matsuzawa et al. 2005), leading to a decreased transepithelial resistance and aberrant TJs. Helicobacter pylori expresses several adhesins that mediate bacterial attachment to gastric epithelial glycan receptors, and possesses a type-IV secretion system that injects the multifunctional bacterial effector CagA into the host cell cytoplasm (Rieder et al. 2005). CagA alters the composition and the function of TJs (Amieva et al. 2003) and leads to a disruption of the epithelial polarity, which could have a role in $H$. pylori-associated carcinogenesis (Saadat et al. 2007).

Toxin A and toxin B from Clostridium difficile are both implicated in the pathogenesis of pseudomembranous colitis (Kuehne et al. 2010). They dissociate TJ's proteins occludin, $\mathrm{ZO}-1$ and ZO-2, thus increasing intestinal epithelium permeability (Voth and Ballard 2005). The bifunctional enterotoxin CPE of Clostridium perfringens, which can cause diarrhea, forms pores in the host cell plasma membrane, and binds claudin-3 and claudin-4 with high affinity (Sonoda et al. 1999; Winkler et al. 2009; Robertson et al. 2010), inducing their degradation, a decrease in transepithelial resistance and disruption of TJs. The role of claudins in the barrier function of TJs was discovered via these studies (Sonoda et al. 1999).

Rotavirus, member of the Reovirus family causing gastroenteritis, also colonizes the gut and disrupts tight junctions. VP8 subunit of VP4, an outer rotavirus protein, moves ZO-1, claudin-3, and occludin from TJs, then disrupting the barrier integrity (Nava et al. 2004; Beau et al. 2007). Similar effects are produced by the viral enterotoxin NSP4, which blocks the formation of TJs by preventing lateral recruitment of ZO-1 (Tafazoli et al. 2001). Reoviruses use the TJ protein JAM-1 as a cellular receptor (Barton et al. 2001). The viral surface protein $\sigma 1$ directly interacts with the amino-terminal domain of JAM-1 and disrupts the homodimers of this junction protein (Forrest et al. 2003; Campbell et al. 2005; Guglielmi et al. 2007).

\section{Active Microbial Crossing of the Intestinal Barrier \\ Translocation across Enterocytes}

Listeria monocytogenes is a facultative intracellular bacterium that crosses the intestinal, bloodbrain and placental barriers, inducing gastroenteritis, meningitis/encephalitis, and maternofetal infection. InlA and InlB, two surface proteins of L. monocytogenes, which interact with their respective host receptors E-cadherin and Met, induce internalization of L. monocytogenes into cultured epithelial cells. Importantly, in contrast to human E-cadherin, mouse E-cadherin is unable to interact with InlA and to promote L. monocytogenes entry into cells (Lecuit et al. 1999, 2001). This species specificity relies on the sixteenth amino acid of the mature Ecadherin, a proline in humans, and a glutamic acid in mice. E-cadherin from guinea pig is also recognized by InlA and harbors a proline at position 16. In this species, contrary to the mouse, L. monocytogenes is able to cross the intestinal barrier, disseminate systemically, and induce a dose- and InlA-dependent lethality (Lecuit et al. 2001). To prove the role of the InlA-E-cadherin interaction in the ability of L. monocytogenes to cross the intestinal barrier, a transgenic mouse model expressing human E-cadherin in post- 
K.S. Doran et al.

mitotic nonproliferative small intestinal enterocytes was designed (Lecuit et al. 2001). In contrast to nontransgenic mice, and similarly to guinea pigs and humans, transgenic mice expressing human E-cadherin are highly permissive to orally acquired listeriosis, demonstrating a critical role for InlA in the ability of L. monocytogenes to cross the intestinal barrier. Epidemiological study of human cases of listeriosis evidence supports this result, because clinical strains express a functional InlA significantly more often $(96 \%)$ than food isolates do $(65 \%)$ (Jacquet et al.2004), which is in favor of a role of InlA in crossing the intestinal barrier in humans. In contrast to the InlA-E-cadherin interaction, the InlB-Met interaction is not necessary for crossing the intestinal barrier in transgenic mice, as well as in gerbil, which is permissive for InlA and InlB (Khelef et al. 2006; Disson et al. 2008). The way by which L. monocytogenes gets access to the adherens junction protein Ecadherin and the mechanism by which bacteria cross the intestinal barrier were not known until recently. It had been proposed that L. monocytogenes access to E-cadherin may be facilitated when extruding epithelial cells detach from the tips of intestinal microvilli, thereby exposing Ecadherin to the luminal side of the intestine (Pentecost et al. 2006). This was shown in vitro and correlated with a colocalization of bacteria with extruding cells in rabbit ileal loop in vivo. It has now been shown that E-cadherin is luminally accessible not only around extruding enterocytes at the tip and lateral sides of villi, but also particularly around mucus-expelling goblet cells (GCs) and in villus epithelial folds. $L$. monocytogenes preferentially adheres to accessible E-cadherin on GCs in a ligated loop of transgenic mice expressing human E-cadherin, is internalized, rapidly transcytosed across the intestinal epithelium, and released in the lamina propria by exocytosis from where it disseminates systemically (Nikitas et al. 2011). L. monocytogenes is thus able to exploit intrinsic tissue heterogeneity to access its receptor. These results highlight transcytosis as an unexpected pathway that is hijacked by L. monocytogenes to breach the intestinal barrier and cause systemic infection. The precise mechanism by which L. mono- cytogenes transcytoses across enterocytes is currently being investigated.

Some viral species also use basolateral cell adhesion molecules as receptors to infect epithelia. The coxsackievirus and adenovirus receptor (CAR) is a component of the tight junction, which is located under the classical TJ proteins (occludin and claudin) and is thus inaccessible to viruses that contact host cells via their apical surface (Freimuth et al. 2008). As indicated by its name, it is both targeted by adenovirus and coxsackieviruses, leading to a decrease in epithelial impermeability (Bergelson et al. 1997). Coxsackieviruses B are members of the Enterovirus family and the causative agents of meningitis and myocarditis. Coxsackievirus-B infects polarized cell layers through binding to the decay-accelerating factor (DAF) proteins on the apical cell surface (Coyne and Bergelson 2006). Virus attachment to DAF leads to the activation of the src kinase Abl, inducing a Rac-dependent reorganization of the actin cytoskeleton that enables the viruses to relocalize to tight junctions. Once in the junction, viral particles interact with CAR, and are internalized in caveolar vesicles, a mechanism dependent on the activation of Fyn kinase by DAF (Coyne and Bergelson 2006). Internalization of coxsackievirus- $B$ also requires the $\mathrm{TJ}$ protein occludin (Coyne et al. 2007). The subsequent release from epithelial cells has been suggested to occur through a calcium signal and calpain-dependent necrosis of the infected cells (Bozym et al. 2011).

\section{Host Cell Sensing of Intestinal Lumen Content as an Achilles' Heel Exploited by Microbes}

$\mathrm{M}$ cells, which are specialized epithelial cells located at the Peyer's patch level and in villi and $\mathrm{CD} 11 \mathrm{c}^{+} \mathrm{CX} 3 \mathrm{CR} 1^{\text {high }}$ cells, continuously sample the intestinal lumen and transport antigens to the mucosal lymphoid tissues (Rescigno 2011). This process is required to either induce tolerance or to initiate immune responses. However, many microbes exploit $\mathrm{M}$ cells as an Achilles' heel to enter the lamina propria, including enteroviruses, Yersinia enterocolitica, Shigella flexneri, and Salmonella enterica (Corr et al. 2008). 
S. enterica causes severe diseases in humans, ranging from gastroenteritis to systemic infections (typhoid fever). Systemic infections because of Salmonella serovars are species-specific: S. enterica serovar Typhi (S. Typhi) induce typhoid fever, a systemic infection in human, whereas S. enterica serovar Typhimurium ( $S$. Typhimurium), which induces a self-limited gastroenteritis in immunocompetent humans, but causes a typhoid-like systemic infection in mice. For this reason, mice have been widely used to study typhoid fever (Monack et al. 2004), although they are generally more resistant than humans to intestinal colonization by S. enterica. To circumvent this limitation, a streptomycin pretreated mouse model of enterocolitis has been developed that allows probing the host and bacterial factors contributing to intestinal immunopathology (Grassl and Finlay 2008). After oral ingestion, $S$. Typhimurium invades intestinal tissues and induces mucosal inflammation. It may enter the blood circulation and infect downstream organs such as liver and spleen (Watson and Holden 2010). S. Typhimurium exploits both dendritic cells and $\mathrm{M}$ cells to access the lamina propria. It was shown that, in the terminal ileum of mice, CD11c ${ }^{+}$(mainly CX3CR $1^{\text {high }}$ ) lamina propria monocytic phagocytes extend protrusions across the epithelium, which facilitates pathogen transport from the gut lumen into the lamina propria (Rescigno et al. 2001; Niess et al. 2005; Chieppa et al. 2006). DCs may then allow the clearance of the pathogen, but in an immunocompromised host may lead to the subsequent colonization of deeper organs. However, sampling by DCs alone does not account for the translocation of $S$. Typhimurium to the lamina propria (Hapfelmeier et al. 2008). S. Typhimurium is also able to translocate through M cells to access Peyer's patches lamina propria (Jones et al. 1994). The glycoprotein 2 (GP2), specifically expressed on the apical plasma membrane of $\mathrm{M}$ cells, recognizes FimH, a component of type-I pili expressed by Enterobacteriaceae, including Escherichia coli and $S$. Typhimurium, which allows the internalization of these bacteria (Hase et al. 2009). Another protein, encoded by $l p f$ from the fimbrial operon, interacts with mouse $M$ cells (Baumler et al. 1996). Once attached, Salmonella pathogenicity island 1 (SPI-1), which codes for bacterial proteins translocated into target cells by the SPI-1 type-III secretion system (TTSS-1), promotes bacterial invasion of mouse M cells (Clark et al. 1998). S. Typhimurium may also cross the intestinal barrier through the epithelial cells in an SPI-1 dependent manner. Recently, the mechanism by which $S$. Typhimurium crosses the epithelial barrier at the cecal level and is released in the lamina propria has been studied in detail (Muller et al. 2012). It has been shown by use of in vivo confocal microscopy in a murine Salmonella-diarrhea model that the breaching of the epithelial barrier relies on both TTSS-1-mediated invasion and TTSS-2-dependent transcytosis to the basolateral side. Once in the lamina propria, the bacterium is transiently extracellular before being phagocytized, among others by CD11c ${ }^{+} \mathrm{CX} 3 \mathrm{CR} 1^{\text {high }}$ monocytic phagocytes, which enables it to colonize the lamina propria. $S$. Typhimurium may then exploit the immune surveillance after crossing the epithelial barrier to infect its host.

\section{Paracellular Pathway}

Pathogens such as parasites (Entamoeba histolytica and Toxoplasma gondii) (Yoshida et al. 2011) or bacteria (Streptococcus agalactiae) have been proposed to cross the intestinal barrier in a paracellular route. This serves to target intercellular junctions and to actively propel between two cell membranes. Toxoplasma gondii $(\mathrm{Tg})$ is a human parasite with the capacity to actively cross not only the intestinal barrier but also the blood-brain and placental barriers (Barragan and Sibley 2003). Tg parasites have been shown to accumulate around intercellular junctions. They may use the paracellular route to cross epithelial barriers without altering the barrier permeability. Crossing may occur through the interaction of the $\mathrm{Tg}$ surface adhesin MIC2 with the intercellular adhesion molecule 1 (ICAM1 ), which is present in the apical surfaces of epithelial barriers (Barragan et al. 2005) and requires the motility property of the parasite (Barragan and Sibley 2002). Tg has to be inter- 
K.S. Doran et al.

nalized by host cells to replicate, and its entry and the formation of a parasitophorous vacuole depend on the association of its apical tip with the host cell through the parasite transmembrane protein AMA1, and a subsequent rearrangement of the host and $\mathrm{Tg}$ cytoskeletons. This allows the parasite to replicate at the intestinal level, and could also be the first step for the invasion of downstream organs (Tyler and Boothroyd 2011).

Streptococcus agalactiae (group B Streptococcus [GBS]) is a normal constituent of the intestinal microflora and the major cause of human neonatal meningitis. Among the GBS clones, ST-17 is strongly associated with meningitis in infants. It has been shown that a ST-17-specific surface-anchored protein called hypervirulent GBS adhesin (HvgA) is required for intestinal colonization and translocation across the intestinal barrier and the blood-brain barrier (BBB), leading to meningitis (Tazi et al. 2010). The mechanism by which the ST-17 clone crosses the intestinal barrier is still unknown. However, previous data suggest that the paracellular route could be a way for GBS to cross epithelial barriers. Using differentiated epithelial cells grown on Transwell inserts as a model, it has been shown by transmission electron microscopy that GBS interacts with intercellular junctions and has the capacity to cross the monolayer by a paracellular mechanism via an active and transient opening of cell junctions (Soriani et al. 2006). This process depends on the pilus backbone of GBS, but the host receptors are still not known (Pezzicoli et al. 2008). However, the mechanism by which the ST-17 clone crosses the intestinal barrier is currently unknown.

\section{MICROBES AND THE PLACENTAL BARRIER}

The human maternofetal barrier contains two anatomically distinct components, the chorioallantoic placenta and the chorioamnion. The barrier is formed at the placental level by specialized epithelial cells, the villous syncytiotrophoblasts, which are differentiated from underlying mononuclear cytotrophoblasts. Multinucleated syncytiotrophoblasts are in direct contact with maternal blood circulating in the intervillous space. A basement membrane separates these trophoblastic cells from a connective tissue that contains fetal capillaries. The amniotic epithelium forms the maternofetal interface in the chorioamnion. The apical surface of this epithelium is exposed to amniotic fluid, whereas its basal surface sits on a basement membrane that overlies the amniotic mesoderm (Cross et al. 1994; Huppertz 2008; Maltepe et al. 2010).

A number of pathogens invade the placenta but few are known to actively cross the placental barrier and disseminate to the fetus. Infection of placenta can lead to abortion, premature delivery, and fetal and neonatal infection. Coxiella burnettii, the agent of $\mathrm{Q}$ fever, is an intracellular bacterium which may infect trophoblast (Baumgartner and Bachmann 1992; Ben Amara et al. 2010) and, in rare cases, the fetus (Carcopino et al. 2009) leading to abortion and premature delivery. Plasmodium falciparum, the etiological agent of the malaria, has long been known to affect pregnancy (Brabin et al. 2004). Parasitized erythrocytes bind to chondroitin sulfate A expressed at the syncytiotrophoblast apical surface, where they accumulate, impeding the physiological functions of the placenta (Scherf et al. 2001). Adverse outcomes are low birth weight babies, fetal loss, as well as increased perinatal and maternal mortality. Several Chlamydia spp, such as Chlamydia trachomatis, Chlamydophila abortus, Chlamydophila psittaci, and Chlamydophila pneumonia are involved in adverse pregnancy outcomes in humans and/or animals (Baud et al. 2008). These obligate intracellular bacteria have been shown to infect trophoblasts in a mouse model of infection, probably via infected maternal neutrophils (Buendia et al. 1998).

The exact mechanism by which pathogens may cross the placental barrier and infect the fetus remain often elusive. The mechanisms by which some of the microorganisms responsible for maternofetal infections in human may cross this barrier are described below.

$\mathrm{Tg}$ is responsible for congenital infection in up to $30 \%$ of infected pregnant women, when primary infection is acquired during pregnancy. $\mathrm{Tg}$ has been shown to infect directly primary human trophoblasts (Abbasi et al. 2003) and 
extravillous trophoblasts of human ex vivo inoculated placental explants (Robbins et al. 2012), as well as trophoblasts in a rodent animal model (Calomys callosus) (Ferro et al. 2002). This invasion may be the critical event leading to the infection of the fetus. Another nonexclusive hypothesis is that $\mathrm{Tg}$ crosses the placental barrier in a paracellular way through the interaction between the parasite adhesin MIC2 and ICAM-1 (Barragan et al. 2005), ICAM-1 being up-regulated during the infection (Juliano et al. 2006).

Brucella abortus $(\mathrm{Ba})$ is an intracellular bacterium that infects animals and humans, inducing a fetal abortion. $\mathrm{Ba}$ is thought to be transmitted in cows via the oro-pharyngeal route after exposure to infected placenta released on abortion. It colonizes placenta in its natural hosts (Carvalho Neta et al. 2010) as well as giant trophoblasts in a mouse animal model (Tobias et al. 1993; Kim et al. 2005b). It could be transmitted to the fetus, indicating a crossing of the placental barrier. A surface protein of $B a$ (SP41) is associated with adherence to and invasion of nonphagocytic HeLa cells (Castaneda-Roldan et al. 2006). However, the receptor is not known and trophoblasts may express other receptors recognized by $\mathrm{Ba}$. The exact mechanism by which $\mathrm{Ba}$ may cross the placental barrier is not known.

Coxsackieviruses B (CVB) may be transmitted to the fetus during delivery (Moore 1982) but the rate of transplacental transmission although present (Konstantinidou et al. 2007), is not known. In a study conducted by Satosar et al. (2004) it was shown that CVB was present in $35 \%$ of infected placentae obtained from cases with fetal or neonatal death or severe neonatal morbidity, indicating a potential strong role of coxsackieviruses in placental infection. It is not known, however, if the mechanism by which CVB crosses the fetal barrier has similarities with crossing of other host barriers (intestinal barrier and BBB).

Rubella virus, which belongs to the Togaviridae family, is associated with congenital rubella syndrome (CRS), a major cause of developmental abnormalities, including blindness and deafness (Banatvala and Brown 2004; Duszak 2009).
Despite efficient vaccination programs, this disease still affects some areas in developing countries. Infection by Rubella virus occurs by inhalation, the placenta being subsequently infected, leading to focal necrosis of the epithelium in the chorionic villi and in the endothelial cells of its capillaries (Tondury and Smith 1966). Despite the existence of animal models of vertical transmission (Cotlier et al. 1968; Kono et al. 1969), the pathophysiology of the infection remains mostly elusive. It has been proposed that infected cells in the placenta detach into the lumen of vessels, resulting in infection and damage of fetal organs. As classically observed for vertically transmitted microbes, symptoms associated with CRS are more severe when the infection occurs during the first trimester of gestation but the infection can occur throughout the pregnancy (Grillner et al. 1983; Miller 1991).

The recent reemergence of another member of the Togaviridae family that belongs to the Alphavirus genus, Chikungunya virus, led to the demonstration that it is associated with severe neonatal infections, including encephalopathy. As mother-to-child transmission is rare in antepartum but frequent in the context of intrapartum maternal viremia, and the placenta is not a site of viral replication, this favors a model of vertical transmission via placental breaches that forms around the term during parturition, as described for a number of other viruses associated with elevated maternal viremia during delivery, such as HIV, HBV, and arboviruses such as Dengue virus or West Nile virus (Couderc et al. 2008; Gerardin et al. 2008).

L. monocytogenes actively crosses the placental barrier and causes severe maternofetal infections in humans (Mylonakis et al. 2002; Lecuit et al. 2007). The ability of L. monocytogenes to infect cytotrophoblastic and syncytiotrophoblastic cells has been shown from immunohistopathological studies of placentas from women with listeriosis, in conjunction with the use of human primary trophoblasts and third trimester human placental explants (Lecuit et al. 2004). Importantly, and in contrast to what is observed at the intestinal barrier level, both InlA and InlB 
K.S. Doran et al.

interactions with their receptors on syncytiotrophoblasts are necessary for efficient invasion (Lecuit et al. 2004). These findings suggest that L. monocytogenes crossing of the human fetoplacental unit follows a transplacental route, after attachment to and invasion of the syncytiotrophoblasts in an InlA- and InlB-dependent manner, respectively. It has been recently proposed in an ex vivo model of human first trimester placental explant that L. monocytogenes enter the placenta in an InlA-dependent manner mostly through the extravillous trophoblasts, which anchor the placenta in the decidua, and not through the syncytiotrophoblasts (Robbins et al. 2010). This apparent difference may be because of intrinsic anatomical differences in first and third trimester explants, the former presenting with more anchoring villi and extravillous trophobalsts than the latter. Of note, infection of fetus and abortion because of $L$. monocytogenes occur far more frequently during later stages of pregnancy ( $\sim 80 \%$ of maternofetal listeriosis occur after 22 weeks of amenorrhea; data from the French National Reference Center for Listeria). The requirement of InlA in L. monocytogenes crossing of the placental barriers has been independently shown epidemiologically, because L. monocytogenes isolates expressing a functional InlA are very significantly associated with their fetoplacental origin (Jacquet et al. 2004; Disson et al. 2008). The mechanism of infection has also been studied in animal models in vivo. As previously described, a limitation to the study of $L$. monocytogenes in vivo is that InlA and InlB interactions with their respective receptors are species-specific: InlA interacts with guinea pig E-cadherin, as in human, but not mouse and rat, E-cadherin (Lecuit et al. 1999), whereas InlB interacts with mouse Met, as in human but not guinea pig Met (Khelef et al. 2006). In apparent contradiction with the above epidemiological, ex vivo and in vitro results, InlA plays no role in $L$. monocytogenes fetoplacental infection in the guinea pig, despite its permissiveness to the InlA pathway (Bakardjiev et al. 2004). Similarly, InlB plays no role in L. monocytogenes fetoplacental infection in the mouse, despite its permissiveness to the InlB pathway (Le Monnier et al. 2007). To investigate the role of both InlA and InlB in vivo, studies were conducted in two complementary animal models permissive for these two pathways: the gerbil, a natural host for L. monocytogenes, and a knockin mouse line that expresses a humanized version of E-cadherin in place of endogenous mouse E-cadherin. Using these two models, it has been established that L. monocytogenes specifically targets the placenta in vivo, in an InlA and InlB interdependent manner, and interacts with its receptors E-cadherin and Met, thereby deciphering the molecular mechanism underlying the ability of L. monocytogenes to target and cross the placental barrier (Disson et al. 2008).

\section{CENTRAL NERVOUS SYSTEM PATHOGENS AND THE BLOOD-BRAIN BARRIER}

Infectious meningitis is a severe and potentially lethal infection of the meninges, the protective membranes covering the central nervous system (CNS), even in otherwise healthy children or adults. Clinical and neuropathologic studies have clearly documented the complications of bacterial meningitis, which are brain edema, increased intracranial pressure, seizure, arterial and venous cerebral vascular insults, and other motor, sensitive, sensorial, and cognitive sequelae (Scheld et al. 2002). Host immune responses are frequently inadequately tuned to control infection within the CNS, either insufficient and unable to control microbial burden, or excessive and associated with excessive inflammation and irreversible tissue damages (Tunkel and Scheld 1995; Pfister and Scheld 1997). In this context, disruption of the BBB is a hallmark event in the pathophysiology of meningitis and subsequent CNS disease, which is critical not only for microbial access to the CNS, but also in the control of the infection.

The BBB maintains the homeostasis of the CNS microenvironment by restricting access of macromolecules, cells, and pathogens. The BBB sensu stricto is anatomically represented by the cerebral microvascular endothelium. Epithelial cells of the choroid plexus and meningeal vessels are two additional potential sites of crossing the blood-cerebrospinal fluid barrier. Brain micro- 
vascular endothelial cells (BMEC) are held together by tight junctions, display a paucity of pinocytosis, and thus form a barrier (Betz 1985, 1992). Yet, despite its highly restrictive nature, certain pathogens are able to penetrate the BBB and gain entry into the CNS. The exact mechanisms by which these microorganisms pass through the BBB result from a complex interplay between host and microbial factors. Two principal mechanisms, operating individually or in tandem, are an increased permeability of the barrier and the direct invasion of the microorganism. The reasons for increased permeability of the BBB during infections are not fully understood. A dose- and time-dependent increase in permeability was observed in various animal models of bacterial meningitis (Temesvari et al. 1993; Kim et al. 1997; Mayhan 1998). These data suggest a role for bacterial factors, like cell wall components and toxins, in promoting BBB permeability either directly or indirectly through induction of host factors. Several reports have linked increased BBB permeability to a parallel increase in levels of circulating cytokines in the blood and CSF during infection (Lo et al. 1994). Tumor necrosis factor $\alpha$ (TNF$\alpha)$, IL-1, and IL-6 are major early response cytokines that trigger a cascade of inflammatory mediators, including other cytokines, chemokines, arachidonic acid metabolites, and reactive nitrogen and oxygen intermediates (Dinarello 2000).

\section{Blood-Brain Barrier Composition}

The BBB, composed primarily of a specialized layer of BMEC, separates the brain and its surrounding tissues from the circulating blood, tightly regulating the flow of nutrients and molecules and thereby maintaining the proper biochemical conditions for normal brain function (Betz 1985, 1992). In addition, other periendothelial structures, such as pericytes, astrocytes, and a basement membrane, contribute to the BBB function (Abbott et al. 2010). These cells function in a coordinated fashion to regulate the passage of nutrients and other small lipophlic molecules while restricting the access of other macromolecules (Pfister et al. 1992; Rubin and
Staddon 1999). The brain endothelial cells are mainly characterized by the presence of tight intercellular junctions that promote high transendothelial electrical resistance and therefore impede paracellular flux of macromolecules (Ballabh et al. 2004). Similar to epithelial cells, endothelial cells express adherens junctions (AJ) and tight junctions (TJ) proteins at sites of intercellular contacts (Schulze and Firth 1993; Wolburg and Lippoldt 2002). In BMEC, TJ are composed of four integral membrane proteins: occludin, claudins, junctional adhesion molecules, and cell-selective adhesion molecules, which are linked through cytoplasmic proteins (zonala-occludin-1 (ZO-1), -2, -3, cingulin) to the actin cytoskeleton. AJ are composed of VE-cadherins, which are connected to actin cytoskeleton through catenins (Furuse 2010; Lampugnani et al. 1995; Hirase et al. 1997; Martin-Padura et al. 1998; Rudini and Dejana 2008). Claudin $1,-3,-5$, and -12 have been identified at the BBB with claudin- 5 being especially critical for BBB formation (Nitta et al. 2003), whereas occludin specifically regulates calcium flux between the blood and brain (Liebner et al. 2008). In addition to maintaining endothelial integrity for normal homeostasis these junctional complexes also play important roles in the maintenance of cell polarity, signaling, and modulation of transcription (Bazzoni and Dejana 2004; Dejana 2004).

\section{Pathogen Invasion of the BBB}

Significant progress has been made in understanding the molecular interactions between the $\mathrm{BBB}$ and microbial pathogens with the availability of in vitro tissue culture models of human BMEC (hBMEC) (Stins et al. 1994; Weksler et al. 2005) and in vivo animal models (Smith et al. 1973; Doran et al. 2002; Wickham et al. 2007; Uchiyama et al. 2009; Sheen et al. 2010). Microbial interactions with the BBB may involve crossing of BMEC in a vacuole (transcytosis), through the intercellular junctional spaces (paracytosis), or while inside a host cell (e.g., infected phagocyte) using it as a vehicle to cross the barrier (Trojan horse) (Kim 2008, 2010) (Fig. 2). 
K.S. Doran et al.

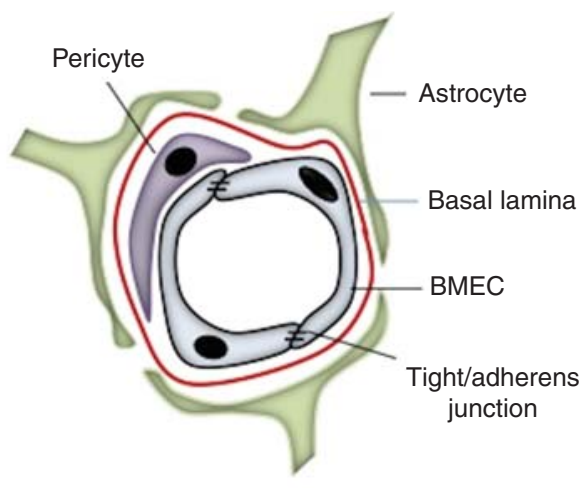

BBB

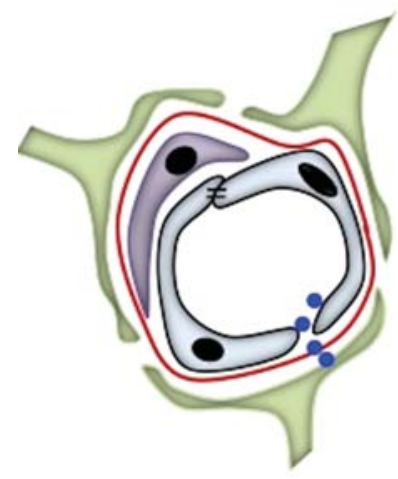

Paracytosis

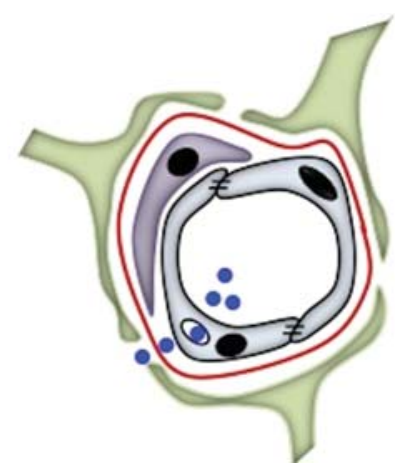

Transcytosis

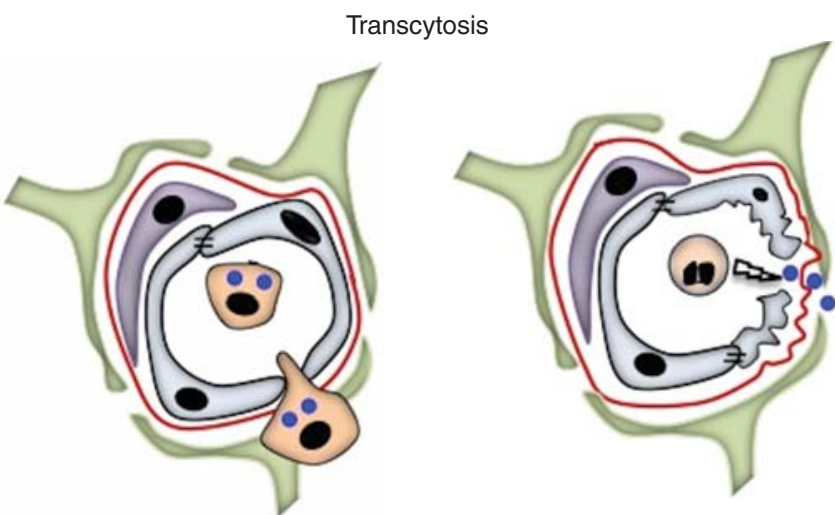

Phagocyte-facilitated invasion

BBB breakdown

Figure 2. (Top left) The blood-brain barrier (BBB) is composed of brain microvascular endothelial cells (BMEC), expressing tight junctions and surrounded by pericytes and astrocytes. From top to bottom and from left to right: Pathogens crossing of the BBB may occur in a vacuole (trancytosis), through intercellular junctional spaces (paracytosis), through an infected blood circulating cell (Trojan's Horse mechanism), or following the barrier disruption (BBB breakdown).

\section{Microbial Adhesion to BMEC and Transcytosis across the $B B B$}

Many meningeal pathogens are able to enter or "invade" brain endothelium apically and exit the cell on the basolateral side, thereby crossing the BBB cellularly. The engagement of host cell receptors results in signaling processes that drive massive host actin cytoskeletal rearrangement to promote bacterial uptake into the cell. Electron microscopic (EM) studies have shown the presences of meningeal pathogens in membrane bound vacuoles within BMEC, suggesting the involvement of endocytic pathways as well as avoidance of lysosomal fusion for BBB traversal (Nizet et al. 1997; van Sorge et al. 2008, 2011). Many studies have focused on the identifica- tion of bacterial and host components involved in microbial interactions with the BBB (Kim 2008). Critical bacterial components have been discovered by screening random mutant libraries (Badger et al. 2000; Doran et al. 2005), analyzing bacterial transcription profiles during infection (Dietrich et al. 2003; Teng et al. 2005), and using bioinformatic approaches for whole genome comparisons (Uchiyama et al. 2009; van Sorge et al. 2009; Tazi et al. 2010). Bacterial pili, or fimbriae, have emerged as a common class of adhesins used by many meningeal pathogens, such as E. coli K1(Teng et al. 2005), GBS (Maisey et al. 2007; van Sorge et al. 2009), and N. meningitides (Kirchner and Meyer 2005) to initiate attachment to brain endothelium. Other well-characterized or recently described bac- 
terial components such as CbpA and NanA, a surface anchored sialidase, in S. pneumonia (Ring et al. 1998; Uchiyama et al. 2009), lipoteichoic acid and HvgA in GBS (Doran et al. 2005; Tazi et al. 2010), typel fimbriae, OmpA and ibeA/B in E. coli K1 (Prasadarao et al. 1999a,b; Teng et al. 2005), promote brain endothelial cell attachment and subsequent cellular penetration. Separately, bacterial toxins play an important role in microbial interactions with the BBB. In case of E. coli K1, cytotoxic necrotizing factor-1 (CNF-1) activates RhoA resulting in increased invasion of BMEC in vitro and increased penetration of the BBB in vivo (Khan et al. 2002, 2003). In contrast, $\beta$ hemolysin ( $\beta$ $\mathrm{h} / \mathrm{c}$ ) of GBS (Doran et al. 2003; Lembo et al. 2010), pneumolysin of S. pneumonia (Zysk et al. 2001) and HiB lipopolysaccharide (Patrick et al. 1992) all cause apoptosis in brain endothelial cells, which lead to increased BBB permeability and bacterial penetration in vivo.

A broad range of host cell surface receptors have been reported to mediate interaction with pathogens that lead to subsequent cellular penetration in the CNS. The laminin receptor (LR) and platelet activating factor receptor (PAFr) have been identified as common portals of CNS entry for the leading meningeal pathogens such as E. coli K1 (Chung et al. 2003; Kim et al. 2005a), Neisseria meningitidis (Virji et al. 1993), Streptococcus pneumoniae (Ring et al. 1998; Orihuela et al. 2009), and Haemophilus influenzae (Swords et al. 2001). LR was identified to function as a receptor for CNF-1 of E. coli K1 (Chung et al. 2003; Kim et al. 2005a), PilQ and PorA of N. meningitidis, CbpA of S. pneumoniae, and OmpP2 of H. influenzae (Orihuela et al. 2009). The PAFr binds to phosphorylcholine on the bacterial surface, which results in $\beta$-arrestin-mediated invasion of brain endothelial cells (Radin et al. 2005). Inflammatory activation of host cells shifts the targeting of S. pneumoniae to this G-protein-coupled receptor (Cundell et al. 1995). This results in promoting bacterial transcytosis across the cell, whereas non-PAFr-mediated entry shunts bacteria for exit and reentry on the apical surface in a novel recycling pathway (Ring et al. 1998). Integrins are also emerging as common receptors for many meningeal pathogens. Bacteria may engage components of an extracellular matrix to bridge to integrins and initiate integrin signaling pathways. For example, human collagen bridges GBS pili adhesin, PilA, and $\alpha_{2} \beta_{1}$ integrin on BMEC, resulting in bacterial attachment, immune activation, and ultimately penetration of the CNS (Banerjee et al. 2011). Similarly, fibronectin bridges $N$. meningitidis to $\alpha_{5} \beta_{1}$ integrin on BMEC surface enabling bacterial internalization (Unkmeir et al. 2002). Glycan structures, specially glucosaminoglycans (GAG), that interact with integrin signaling machinery, have been shown to interact with bacterial proteins such as the GBS $\alpha$ C protein (Chang et al. 2011). Given that many of these host cell factors preferentially localize to the basolateral surface of polarized endothelium, disruption of junctional protein complexes on infection may result in a nonpolarized distribution of proteins on the $\mathrm{BBB}$ plasma membrane and their luminal accessibility (see below).

\section{Paracytosis}

Several meningeal pathogens are capable of either cleaving or remodeling these intercellular junctional proteins and therefore affect BBB integrity. Disruption of these cellular contacts leads to increased $\mathrm{BBB}$ permeability and also facilitates bacterial translocation into the brain. Bacterial toxins such as pneumolysin and $\beta$-hemolysin, of S. pneumoniae and GBS, respectively, are implicated in directly affecting the BBB integrity by causing endothelial cell death (Zysk et al. 2001; Lembo et al. 2010). For GBS, higher toxin production has been associated with increased capacity to cause meningitis (Doran et al. 2003). In addition, toxin production results in increased production of proinflammatory cytokines/chemokines, especially TNF- $\alpha$, which negatively impact the BBB function (Sharief et al. 1992; Kim et al. 1997; Barichello et al. 2011).

Pathogens may also bind to endothelial cells at or near the TJs (Grab et al. 2004, 2005) and induce the secretion of host proteases that can cleave TJ or AJ proteins. For example, N. meningitidis induces specific cleavage of the TJ com- 
K.S. Doran et al.

ponent occludin through the release of host matrix metalloproteinase 8 , resulting in endothelial cell detachment and increased paracellular permeability (Schubert-Unkmeir et al. 2010). A similar strategy is used by Borrelia, which was shown to degrade TJ proteins and allow passage of monocytes (Reijerkerk et al. 2006). Some pathogens may adopt a more sophisticated strategy of remodeling the junctional complexes. E. coli $\mathrm{K} 1 \mathrm{OmpA}$ initiates a signaling process that leads to the dissociation of $\beta$-catenins from cadherins which further results in disruption of barrier integrity (Sukumaran and Prasadarao 2003). The type-IV pili of $N$. meningitides, on the other hand, stimulates the $\beta 2$-adrenoceptor $/ \beta$-arrestin signaling pathway in endothelial cells, leading to recruitment of the Par3/Par6/PKCל polarity complex and delocalization of junctional proteins which result in anatomical gaps that are used by the bacteria to penetrate into the CNS (Coureuil et al. 2009, 2010). Human immunodeficiency virus (HIV) envelope glycoprotein gp120 has also been shown to increase BBB permeability by interacting with endothelial trans-membrane coreceptor CCR5 and CXCR4 (Kanmogne et al. 2007).

\section{Phagocyte-Facilitated Invasion}

The use of phagocytic cells for BBB invasion (Trojan horse mechanism) appears to be mainly used by intracellular pathogens that are able to survive and eventually multiply in professional phagocytes. According to this scenario, a pathogen first infects a bone-marrow-derived cell, such as a macrophage, monocyte, or dendritic cell, which may then penetrate the BBB, acting as a shuttle for the microbe. For example, CD11b expressing cells are infected and used by $T$. gondii to breach the BBB (Lachenmaier et al. 2011). Similarly, monocytes or macrophages may be used by C. neoformans, L. monocytogenes, M. tuberculosis, and Brucella and Salmonella spp for entry into the CNS (Greiffenberg et al. 1998; Drevets et al. 2004; JoinLambert et al. 2005; Charlier et al. 2009). West Nile virus infection of BMEC modulates TJ proteins in endothelial cells and facilitates migra- tion of virus-infected cells through that space into CNS (Verma et al. 2009). HIV infection of monocytes increases surface expression of LFA-1, an ICAM1 ligand that increases the likelihood of adhesion to CNS endothelial cells (Stent and Crowe 1997). After penetration, these infected monocytes and macrophages can spread the pathogen to microglia, perivascular macrophages, and astrocytes, creating a reservoir for the organism in the CNS. These parenchymal pathogen reservoirs primarily result in microglial activation, leukocyte infiltration into the CNS, and neuronal damage.

\section{Inflammation and BBB Permeability}

Finally, host inflammatory factors may also contribute to loss of BBB integrity, resulting in pathogen penetration into the CNS. It was recently shown that polymorphonuclear neutrophils contribute to BBB impermeability loss during the GBS meningitis (Banerjee et al. 2011). Although neutrophils are critically important to fight against bacterial sepsis, depletion of peripheral neutrophils in a murine hematogenous model of GBS meningitis prolonged survival, decreased bacterial CNS load, and decreased BBB leakage in GBS-infected mice (Banerjee et al. 2011). Correspondingly, prevention of leukocyte infiltration into the CNS using antiCD18 antibody has been shown to improve pneumococcal and $\mathrm{HiB}$ meningitis outcomes (Tuomanen et al. 1989; Saez-Llorens et al. 1991).

Different bacterial components initiate inflammatory activation of brain endothelial cells, resulting in secretion of cytokines and chemokines such as TNF- $\alpha$, IL- 1 , IL- 8 , or TGF- $\beta$, the levels of which are typically elevated in meningitis patients (Waage et al. 1989; Fida et al. 2006; Nagesh Babu et al. 2008). These cytokines may have an autocrine effect on BMEC, leading to increased expression of host receptors that further promote bacterial penetration. For example, cells stimulated with TNF- $\alpha$, IL-8, or TGF$\beta$ resulted in an increased bacterial uptake in vitro (Cundell et al. 1995; Zhang et al. 2002; Banerjee et al. 2010). OmpA of E. coli K1 binds to gp96 glycoprotein on BMEC surface and this interaction in turn increases the expression of 
type-1 fimbriae that bind to CD48 (Prasadarao et al. 2003; Khan et al. 2007). Pathogen interaction with BMEC also results in activation of several signal transduction pathways that either leads to actin cytoskeleton rearrangement and subsequent bacterial uptake or proinflammatory chemokine/cytokine secretion and localized inflammation. In the majority of instances actin cytoskeleton rearrangement signaling events involve activation of focal adhesion kinase (FAK) (Prasadarao et al. 1999b; Banerjee et al. 2011), phosphatidylinositol 3-kinase (PI3K), $\rho$ GTPases (Khan et al. 2003) and cytosolic phospholipase A2 (Das et al. 2001) $\left(\mathrm{CPLA}_{2}\right)$, and src kinases (Slanina et al. 2010). Additionally, activation of mitogen-activated protein (MAP) kinase signaling pathways promotes proinflammatory cytokine secretion (Sokolova et al. 2004; Banerjee et al. 2010, 2011).

Transcriptional analysis of the BMEC on GBS infection revealed a specific gene-activation program acting to orchestrate neutrophil recruitment (IL-8, CXCL1, CXCL2), activation (IL-6, IL-8), survival (GM-CSF), and extravasation (ICAM-1). This response was dependent on the GBS $\beta-h / c$ toxin, the transcriptional regulator of virulence, CovR and PilA expression (Doran et al. 2003; Lembo et al. 2010; Banerjee et al. 2011). Additional in vitro studies with $S$. pneumoniae, HiB, S. typhimurium, E. coli K1, Streptococcus suis, L. monocytogenes, and $N$. meningitidis reveal a similar core BMEC transcriptional response that results in the induction of neutrophil signaling pathways (Wilson and Drevets 1998; Vadeboncoeur et al. 2003; Galanakis et al. 2006; Schubert-Unkmeir et al. 2007; Banerjee et al. 2010; van Sorge et al. 2011). Continued exposure and invasion of the pathogen may result in overactivation of $\mathrm{BBB}$ endothelium and lead to increased inflammation that may ultimately compromise BBB integrity.

\section{IN SUMMARY}

Microbial interactions with host barriers are key events in invasive infectious diseases. The deciphering of the molecular mechanisms underlying microbial attachment to, invasion of, translocation across, and disruption of host barriers is not only important in a biomedical perspective but also on a basic perspective. Future studies will hopefully help improve the severe prognosis of invasive infection, and also contribute to a better understanding of the physiology of host barriers.

\section{ACKNOWLEDGMENTS}

The authors thank their respective laboratory members for their help and support and apologize to researchers whose work has not been discussed in detail or reviewed here because of space constraints. Work on the BBB and bacterial meningitis in K.S.D.'s laboratory is supported by funding from the National Institutes of Health/National Institute of Neurological Disorders and Stroke (grant No. RO1NS051247). Work in M.L's laboratory is supported by Institut Pasteur, INSERM, ERC, FRM, Ville de Paris, Labex IBEID, Listress, and ICRES EU Programs and Fondation BNP-Paribas. The authors declare no competing financial interests.

\section{REFERENCES}

Abbasi M, Kowalewska-Grochowska K, Bahar MA, Kilani RT, Winkler-Lowen B, Guilbert LJ. 2003. Infection of placental trophoblasts by Toxoplasma gondii. J Infect Dis 188: $608-616$.

Abbott NJ, Patabendige AA, Dolman DE, Yusof SR, Begley DJ. 2010. Structure and function of the blood-brain barrier. Neurobiol Dis 37: 13-25.

Amieva MR, Vogelmann R, Covacci A, Tompkins LS, Nelson WJ, Falkow S. 2003. Disruption of the epithelial apicaljunctional complex by Helicobacter pylori CagA. Science 300: $1430-1434$.

Anderson JM, Van Itallie CM, Fanning AS. 2004. Setting up a selective barrier at the apical junction complex. Curr Opin Cell Biol 16: 140-145.

Badger JL, Wass CA, Kim KS. 2000. Identification of Escherichia coli $\mathrm{K} 1$ genes contributing to human brain microvascular endothelial cell invasion by differential fluorescence induction. Mol Microbiol 36: 174-182.

Bakardjiev AI, Stacy BA, Fisher SJ, Portnoy DA. 2004. Listeriosis in the pregnant guinea pig: A model of vertical transmission. Infect Immun 72: 489-497.

Ballabh P, Braun A, Nedergaard M. 2004. The blood-brain barrier: an overview: Structure, regulation, and clinical implications. Neurobiol Dis 16: 1-13.

Banatvala JE, Brown DW. 2004. Rubella. Lancet 363: $1127-$ 1137.

Banerjee A, Van Sorge NM, Sheen TR, Uchiyama S, Mitchell TJ, Doran KS. 2010. Activation of brain endothelium by 


\section{K.S. Doran et al.}

pneumococcal neuraminidase NanA promotes bacterial internalization. Cell Microbiol 12: 1576-1588.

Banerjee A, Kim BJ, Carmona EM, Cutting AS, Gurney MA, Carlos C, Feuer R, Prasadarao NV, Doran KS. 2011. Bacterial Pili exploit integrin machinery to promote immune activation and efficient blood-brain barrier penetration. Nat Commun 2: 462.

Barichello T, Pereira JS, Savi GD, Generoso JS, Cipriano AL, Silvestre C, Petronilho F, Dal-Pizzol F, Vilela MC, Teixeira AL. 2011. A kinetic study of the cytokine/chemokines levels and disruption of blood-brain barrier in infant rats after pneumococcal meningitis. J Neuroimmunol 233: $12-17$.

Barragan A, Sibley LD. 2002. Transepithelial migration of Toxoplasma gondii is linked to parasite motility and virulence. J Exp Med 195: 1625-1633.

Barragan A, Sibley LD. 2003. Migration of Toxoplasma gondii across biological barriers. Trends Microbiol 11: 426430.

Barragan A, Brossier F, Sibley LD. 2005. Transepithelial migration of Toxoplasma gondii involves an interaction of intercellular adhesion molecule 1 (ICAM-1) with the parasite adhesin MIC2. Cell Microbiol 7: 561-568.

Barton ES, Forrest JC, Connolly JL, Chappell JD, Liu Y, Schnell FJ, Nusrat A, Parkos CA, Dermody TS. 2001. Junction adhesion molecule is a receptor for reovirus. Cell 104: 441-451.

Baud D, Regan L, Greub G. 2008. Emerging role of Chlamydia and Chlamydia-like organisms in adverse pregnancy outcomes. Curr Opin Infect Dis 21: 70-76.

Baumgartner W, Bachmann S. 1992. Histological and immunocytochemical characterization of Coxiella burnetiiassociated lesions in the murine uterus and placenta. Infect Immun 60: 5232-5241.

Baumler AJ, Tsolis RM, Heffron F. 1996. The lpf fimbrial operon mediates adhesion of Salmonella typhimurium to murine Peyer's patches. Proc Natl Acad Sci 93: 279-283.

Bazzoni G, Dejana E. 2004. Endothelial cell-to-cell junctions: Molecular organization and role in vascular homeostasis. Physiol Rev 84: 869-901.

Beau I, Cotte-Laffitte J, Amsellem R, Servin AL. 2007. A protein kinase A-dependent mechanism by which rotavirus affects the distribution and mRNA level of the functional tight junction-associated protein, occludin, in human differentiated intestinal Caco-2 cells. J Virol 81: 8579-8586.

Ben Amara A, Ghigo E, Le Priol Y, Lepolard C, Salcedo SP, Lemichez E, Bretelle F, Capo C, Mege JL. 2010. Coxiella burnetii, the agent of $\mathrm{Q}$ fever, replicates within trophoblasts and induces a unique transcriptional response. PLoS ONE 5: e15315.

Bergelson JM, Cunningham JA, Droguett G, Kurt-Jones EA, Krithivas A, Hong JS, Horwitz MS, Crowell RL, Finberg RW. 1997. Isolation of a common receptor for Coxsackie B viruses and adenoviruses 2 and 5. Science 275: 1320 1323.

Betz AL. 1985. Epithelial properties of brain capillary endothelium. Fed Proc 44: 2614-2615.

Betz AL. 1992. An overview of the multiple functions of the blood-brain barrier. NIDA Res Monogr 120: 54-72.
Bozym RA, Patel K, White C, Cheung KH, Bergelson JM, Morosky SA, Coyne CB. 2011. Calcium signals and calpain-dependent necrosis are essential for release of coxsackievirus B from polarized intestinal epithelial cells. Mol Biol Cell 22: 3010-3021.

Brabin BJ, Romagosa C, Abdelgalil S, Menendez C, Verhoeff FH, McGready R, Fletcher KA, Owens S, D’Alessandro U, Nosten F, et al. 2004. The sick placenta-the role of malaria. Placenta 25: 359-378.

Buendia AJ, Sanchez J, Martinez MC, Camara P, Navarro JA, Rodolakis A, Salinas J. 1998. Kinetics of infection and effects on placental cell populations in a murine model of Chlamydia psittaci-induced abortion. Infect Immun 66: $2128-2134$

Campbell JA, Schelling P, Wetzel JD, Johnson EM, Forrest JC, Wilson GA, Aurrand-Lions M, Imhof BA, Stehle T, Dermody TS. 2005. Junctional adhesion molecule a serves as a receptor for prototype and field-isolate strains of mammalian reovirus. J Virol 79: 7967-7978.

Carcopino X, Raoult D, Bretelle F, Boubli L, Stein A. 2009. Q Fever during pregnancy: A cause of poor fetal and maternal outcome. Ann NY Acad Sci 1166: 79-89.

Carvalho Neta AV, Mol JP, Xavier MN, Paixao TA, Lage AP, Santos RL. 2010. Pathogenesis of bovine brucellosis. Vet J 184: 146-155.

Castaneda-Roldan EI, Ouahrani-Bettache S, Saldana Z, Avelino F, Rendon MA, Dornand J, Giron JA. 2006. Characterization of SP41, a surface protein of Brucella associated with adherence and invasion of host epithelial cells. Cell Microbiol 8: 1877-1887.

Chang YC, Wang Z, Flax LA, Xu D, Esko JD, Nizet V, Baron MJ. 2011. Glycosaminoglycan binding facilitates entry of a bacterial pathogen into central nervous systems. PLoS Pathog 7: e1002082.

Charlier C, Nielsen K, Daou S, Brigitte M, Chretien F, Dromer F. 2009. Evidence of a role for monocytes in dissemination and brain invasion by Cryptococcus neoformans. Infect Immun 77: 120-127.

Chieppa M, Rescigno M, Huang AY, Germain RN. 2006. Dynamic imaging of dendritic cell extension into the small bowel lumen in response to epithelial cell TLR engagement. J Exp Med 203: 2841-2852.

Chung JW, Hong SJ, Kim KJ, Goti D, Stins MF, Shin S, Dawson VL, Dawson TM, Kim KS. 2003. 37-kDa laminin receptor precursor modulates cytotoxic necrotizing factor 1-mediated RhoA activation and bacterial uptake. $J$ Biol Chem 278: 16857-16862.

Clark MA, Hirst BH, Jepson MA. 1998. Inoculum composition and Salmonella pathogenicity island 1 regulate Mcell invasion and epithelial destruction by Salmonella typhimurium. Infect Immun 66: 724-731.

Corr SC, Gahan CC, Hill C. 2008. M-cells: Origin, morphology and role in mucosal immunity and microbial pathogenesis. FEMS Immunol Med Microbiol 52: 2-12.

Cotlier E, Fox J, Bohigian G, Beaty C, Du Pree A. 1968 Pathogenic effects of rubella virus on embryos and newborn rats. Nature 217: 38-40.

Couderc T, Chretien F, Schilte C, Disson O, Brigitte M, Guivel-Benhassine F, Touret Y, Barau G, Cayet N, Schuffenecker I, et al. 2008. A mouse model for Chikungunya: Young age and inefficient type-I interferon signaling are risk factors for severe disease. PLoS Pathog 4: e29. 
Coureuil M, Mikaty G, Miller F, Lecuyer H, Bernard C, Bourdoulous S, Dumenil G, Mege RM, Weksler BB, Romero IA, et al. 2009. Meningococcal type IV pili recruit the polarity complex to cross the brain endothelium. Science 325: 83-87.

Coureuil M, Lecuyer H, Scott MG, Boularan C, Enslen H, Soyer M, Mikaty G, Bourdoulous S, Nassif X, Marullo S. 2010. Meningococcus hijacks a $\beta 2$-adrenoceptor $/ \beta$-Arrestin pathway to cross brain microvasculature endothelium. Cell 143: 1149-1160.

Coyne CB, Bergelson JM. 2006. Virus-induced Abl and Fyn kinase signals permit coxsackievirus entry through epithelial tight junctions. Cell 124: 119-131.

Coyne CB, Shen L, Turner JR, Bergelson JM. 2007. Coxsackievirus entry across epithelial tight junctions requires occludin and the small GTPases Rab34 and Rab5. Cell Host Microbe 2: 181-192.

Cross JC, Werb Z, Fisher SJ. 1994. Implantation and the placenta: Key pieces of the development puzzle. Science 266: $1508-1518$.

Cundell DR, Gerard NP, Gerard C, Idanpaan-Heikkila I, Tuomanen EI. 1995. Streptococcus pneumoniae anchor to activated human cells by the receptor for platelet-activating factor. Nature 377: 435-438.

Das A, Asatryan L, Reddy MA, Wass CA, Stins MF, Joshi S, Bonventre JV, Kim KS. 2001. Differential role of cytosolic phospholipase A2 in the invasion of brain microvascular endothelial cells by Escherichia coli and Listeria monocytogenes. J Infect Dis 184: 732-737.

Dean P, Kenny B. 2004. Intestinal barrier dysfunction by enteropathogenic Escherichia coli is mediated by two effector molecules and a bacterial surface protein. Mol Microbiol 54: 665-675.

Dejana E. 2004. Endothelial cell-cell junctions: Happy together. Nat Rev Mol Cell Biol 5: 261-270.

Dietrich G, Kurz S, Hubner C, Aepinus C, Theiss S, Guckenberger M, Panzner U, Weber J, Frosch M. 2003. Transcriptome analysis of Neisseria meningitidis during infection. J Bacteriol 185: 155-164.

Dinarello CA. 2000. Proinflammatory cytokines. Chest 118: 503-508.

Disson O, Grayo S, Huillet E, Nikitas G, Langa-Vives F, Dussurget O, Ragon M, Le Monnier A, Babinet C, Cossart P, et al. 2008. Conjugated action of two species-specific invasion proteins for fetoplacental listeriosis. Nature 455: $1114-1118$.

Doran KS, Chang JC, Benoit VM, Eckmann L, Nizet V. 2002. Group B streptococcal $\beta$-hemolysin/cytolysin promotes invasion of human lung epithelial cells and the release of interleukin-8. J Infect Dis 185: 196-203.

Doran KS, Liu GY, Nizet V. 2003. Group B streptococcal $\beta$ hemolysin/cytolysin activates neutrophil signaling pathways in brain endothelium and contributes to development of meningitis. J Clin Invest 112: 736-744.

Doran KS, Engelson EJ, Khosravi A, Maisey HC, Fedtke I, Equils O, Michelsen KS, Arditi M, Peschel A, Nizet V. 2005. Blood-brain barrier invasion by group B Streptococcus depends upon proper cell-surface anchoring of lipoteichoic acid. J Clin Invest 115: 2499-2507.

Drevets DA, Dillon MJ, Schawang JS, Van Rooijen N, Ehrchen J, Sunderkotter C, Leenen PJ. 2004. The Ly-
6Chigh monocyte subpopulation transports Listeria monocytogenes into the brain during systemic infection of mice. J Immunol 172: 4418-4424.

Duszak RS. 2009. Congenital rubella syndrome-Major review. Optometry 80: 36-43.

Ferro EA, Silva DA, Bevilacqua E, Mineo JR. 2002. Effect of Toxoplasma gondii infection kinetics on trophoblast cell population in Calomys callosus, a model of congenital toxoplasmosis. Infect Immun 70: 7089-7094.

Fida NM, Al-Mughales J, Farouq M. 2006. Interleukin-1 $\alpha$, interleukin- 6 and tumor necrosis factor- $\alpha$ levels in children with sepsis and meningitis. Pediatr Int 48: 118-124.

Forrest JC, Campbell JA, Schelling P, Stehle T, Dermody TS. 2003. Structure-function analysis of reovirus binding to junctional adhesion molecule 1 . Implications for the mechanism of reovirus attachment. J Biol Chem 278: 48434-48444.

Freimuth P, Philipson L, Carson SD. 2008. The coxsackievirus and adenovirus receptor. Curr Top Microbiol Immunol 323: $67-87$.

Furuse M. 2010. Molecular basis of the core structure of tight junctions. Cold Spring Harb Perspect Biol 2: a002907.

Galanakis E, Di Cello F, Paul-Satyaseela M, Kim KS. 2006. Escherichia coli K1 induces IL-8 expression in human brain microvascular endothelial cells. Eur Cytokine Netw 17: 260-265.

Gerardin P, Barau G, Michault A, Bintner M, Randrianaivo H, Choker G, Lenglet Y, Touret Y, Bouveret A, Grivard P, et al. 2008. Multidisciplinary prospective study of motherto-child chikungunya virus infections on the island of $\mathrm{La}$ Reunion. PLoS Med 5: e60.

Grab DJ, Nikolskaia O, Kim YV, Lonsdale-Eccles JD, Ito S, Hara T, Fukuma T, Nyarko E, Kim KJ, Stins MF, et al. 2004. African trypanosome interactions with an in vitro model of the human blood-brain barrier. J Parasitol 90: 970-979.

Grab DJ, Perides G, Dumler JS, Kim KJ, Park J, Kim YV, Nikolskaia O, Choi KS, Stins MF, Kim KS. 2005. Borrelia burgdorferi, host-derived proteases, and the bloodbrain barrier. Infect Immun 73: 1014-1022.

Grassl GA, Finlay BB. 2008. Pathogenesis of enteric Salmonella infections. Curr Opin Gastroenterol 24: 22-26.

Greiffenberg L, Goebel W, Kim KS, Weiglein I, Bubert A, Engelbrecht F, Stins M, Kuhn M. 1998. Interaction of Listeria monocytogenes with human brain microvascular endothelial cells: InlB-dependent invasion, long-term intracellular growth, and spread from macrophages to endothelial cells. Infect Immun 66: 5260-5267.

Grillner L, Forsgren M, Barr B, Bottiger M, Danielsson L, De Verdier C. 1983. Outcome of rubella during pregnancy with special reference to the 17th-24th weeks of gestation. Scand J Infect Dis 15: 321-325.

Guglielmi KM, Kirchner E, Holm GH, Stehle T, Dermody TS. 2007. Reovirus binding determinants in junctional adhesion molecule-A. J Biol Chem 282: 17930-17940.

Guttman JA, Finlay BB. 2009. Tight junctions as targets of infectious agents. Biochim Biophys Acta 1788: 832-841.

Hapfelmeier S, Muller AJ, Stecher B, Kaiser P, Barthel M, Endt K, Eberhard M, Robbiani R, Jacobi CA, Heikenwalder M, et al. 2008. Microbe sampling by mucosal 


\section{K.S. Doran et al.}

dendritic cells is a discrete, MyD88-independent step in $\Delta$ invG S. Typhimurium colitis. J Exp Med 205: 437-450.

Harris TJ, Tepass U. 2010. Adherens junctions: From molecules to morphogenesis. Nat Rev Mol Cell Biol 11: $502-$ 514.

Hase K, Kawano K, Nochi T, Pontes GS, Fukuda S, Ebisawa M, Kadokura K, Tobe T, Fujimura Y, Kawano S, et al. 2009. Uptake through glycoprotein 2 of $\mathrm{FimH}^{+}$bacteria by $\mathrm{M}$ cells initiates mucosal immune response. Nature 462: 226-230.

Hirase T, Staddon JM, Saitou M, Ando-Akatsuka Y, Itoh M, Furuse M, Fujimoto K, Tsukita S, Rubin LL. 1997. Occludin as a possible determinant of tight junction permeability in endothelial cells. J Cell Sci 110: 1603-1613.

Huppertz B. 2008. The anatomy of the normal placenta. J Clin Pathol 61: 1296-1302.

Jacquet C, Doumith M, Gordon JI, Martin PM, Cossart P, Lecuit M. 2004. A molecular marker for evaluating the pathogenic potential of foodborne Listeria monocytogenes. J Infect Dis 189: 2094-2100.

Join-Lambert OF, Ezine S, Le Monnier A, Jaubert F, Okabe M, Berche P, Kayal S. 2005. Listeria monocytogenes-infected bone marrow myeloid cells promote bacterial invasion of the central nervous system. Cell Microbiol 7: 167-180.

Jones BD, Ghori N, Falkow S. 1994. Salmonella typhimurium initiates murine infection by penetrating and destroying the specialized epithelial M cells of the Peyer's patches. J Exp Med 180: 15-23.

Juliano PB, Blotta MH, Altemani AM. 2006. ICAM-1 is overexpressed by villous trophoblasts in placentitis. Placenta 27: 750-757.

Kanmogne GD, Schall K, Leibhart J, Knipe B, Gendelman HE, Persidsky Y. 2007. HIV-1 gp120 compromises blood-brain barrier integrity and enhances monocyte migration across blood-brain barrier: Implication for viral neuropathogenesis. J Cereb Blood Flow Metab 27: $123-134$.

Khan NA, Wang Y, Kim KJ, Chung JW, Wass CA, Kim KS. 2002. Cytotoxic necrotizing factor-1 contributes to Escherichia coli $\mathrm{K} 1$ invasion of the central nervous system. $J$ Biol Chem 277: 15607-15612.

Khan NA, Shin S, Chung JW, Kim KJ, Elliott S, Wang Y, Kim KS. 2003. Outer membrane protein A and cytotoxic necrotizing factor-1 use diverse signaling mechanisms for Escherichia coli $\mathrm{K} 1$ invasion of human brain microvascular endothelial cells. Microb Pathog 35: 35-42.

Khan NA, Kim Y, Shin S, Kim KS. 2007. FimH-mediated Escherichia coli K1 invasion of human brain microvascular endothelial cells. Cell Microbiol 9: 169-178.

Khelef N, Lecuit M, Bierne H, Cossart P. 2006. Species specificity of the Listeria monocytogenes InlB protein. Cell Microbiol 8: 457-470.

Kim KS. 2008. Mechanisms of microbial traversal of the blood-brain barrier. Nat Rev Microbiol.

Kim KS. 2010. Acute bacterial meningitis in infants and children. Lancet Infect Dis 10: 32-42.

Kim KS, Wass CA, Cross AS. 1997. Blood-brain barrier permeability during the development of experimental bacterial meningitis in the rat. Exp Neurol 145: 253-257.

Kim KJ, Chung JW, Kim KS. 2005a. 67-kDa laminin receptor promotes internalization of cytotoxic necrotizing fac- tor 1-expressing Escherichia coli K1 into human brain microvascular endothelial cells. J Biol Chem 280: 13601368.

Kim S, Lee DS, Watanabe K, Furuoka H, Suzuki H, Watarai M. 2005b. Interferon- $\gamma$ promotes abortion due to Brucella infection in pregnant mice. BMC Microbiol 5: 22.

Kirchner M, Meyer TF. 2005. The PilC adhesin of the Neisseria type IV pilus-binding specificities and new insights into the nature of the host cell receptor. Mol Microbiol 56: 945-957.

Kono R, Hayakawa Y, Hibi M, Ishii K. 1969. Experimental vertical transmission of rubella virus in rabbits. Lancet $\mathbf{1}$ : $343-347$.

Konstantinidou A, Anninos H, Spanakis N, Kotsiakis X, Syridou G, Tsakris A, Patsouris E. 2007. Transplacental infection of coxsackievirus B3 pathological findings in the fetus. J Med Virol 79: 754-757.

Kuehne SA, Cartman ST, Heap JT, Kelly ML, Cockayne A, Minton NP. 2010. The role of toxin A and toxin B in Clostridium difficile infection. Nature 467: 711-713.

Lachenmaier SM, Deli MA, Meissner M, Liesenfeld O. 2011. Intracellular transport of Toxoplasma gondii through the blood-brain barrier. J Neuroimmunol 232: 119-130.

Lampugnani MG, Corada M, Caveda L, Breviario F, Ayalon O, Geiger B, Dejana E. 1995. The molecular organization of endothelial cell to cell junctions: Differential association of plakoglobin, $\beta$-catenin, and $\alpha$-catenin with vascular endothelial cadherin (VE-cadherin). J Cell Biol 129: 203-217.

Lecuit M, Dramsi S, Gottardi C, Fedor-Chaiken M, Gumbiner B, Cossart P. 1999. A single amino acid in E-cadherin responsible for host specificity towards the human pathogen Listeria monocytogenes. EMBO J 18: $3956-$ 3963.

Lecuit M, Vandormael-Pournin S, Lefort J, Huerre M, Gounon P, Dupuy C, Babinet C, Cossart P. 2001. A transgenic model for listeriosis: Role of internalin in crossing the intestinal barrier. Science 292: 1722-1725.

Lecuit M, Nelson DM, Smith SD, Khun H, Huerre M, Vacher-Lavenu MC, Gordon JI, Cossart P. 2004. Targeting and crossing of the human maternofetal barrier by Listeria monocytogenes: Role of internalin interaction with trophoblast E-cadherin. Proc Natl Acad Sci 101: 61526157.

Lecuit M, Sonnenburg JL, Cossart P, Gordon JI. 2007. Functional genomic studies of the intestinal response to a foodborne enteropathogen in a humanized gnotobiotic mouse model. J Biol Chem 282: 15065-15072.

Lembo A, Gurney MA, Burnside K, Banerjee A, bfde los Reyes M, Connelly JE, Lin WJ, Jewell KA, Vo A, Renken CW, et al. 2010. Regulation of CovR expression in Group B Streptococcus impacts blood-brain barrier penetration. Mol Microbiol 77: 431-443.

Le Monnier A, Autret N, Join-Lambert OF, Jaubert F, Charbit A, Berche P, Kayal S. 2007. ActA is required for crossing of the fetoplacental barrier by Listeria monocytogenes. Infect Immun 75: 950-957.

Liebner S, Corada M, Bangsow T, Babbage J, Taddei A, Czupalla CJ, Reis M, Felici A, Wolburg H, Fruttiger M, et al. 2008. Wnt $\beta$-catenin signaling controls development of the blood-brain barrier. J Cell Biol 183: 409-417. 
Lo WD, Wolny A, Boesel C. 1994. Blood-brain barrier permeability in staphylococcal cerebritis and early brain abscess. J Neurosurg 80: 897-905.

Maisey HC, Hensler M, Nizet V, Doran KS. 2007. Group B streptococcal pilus proteins contribute to adherence to and invasion of brain microvascular endothelial cells. $J$ Bacteriol 189: 1464-1467.

Maltepe E, Bakardjiev AI, Fisher SJ. 2010. The placenta: Transcriptional, epigenetic, and physiological integration during development. J Clin Invest 120: 1016-1025.

Martin-Padura I, Lostaglio S, Schneemann M, Williams L, Romano M, Fruscella P, Panzeri C, Stoppacciaro A, Ruco L, Villa A, et al. 1998. Junctional adhesion molecule, a novel member of the immunoglobulin superfamily that distributes at intercellular junctions and modulates monocyte transmigration. J Cell Biol 142: 117-127.

Matsuzawa T, Kuwae A, Abe A. 2005. Enteropathogenic Escherichia coli type III effectors EspG and EspG2 alter epithelial paracellular permeability. Infect Immun 73: 6283-6289.

Mayhan WG. 1998. Effect of lipopolysaccharide on the permeability and reactivity of the cerebral microcirculation: Role of inducible nitric oxide synthase. Brain Res 792: 353-357.

Miller E. 1991. Rubella in the United Kingdom. Epidemiol Infect 107: 31-42.

Monack DM, Mueller A, Falkow S. 2004. Persistent bacterial infections: The interface of the pathogen and the host immune system. Nat Rev Microbiol 2: 747-765.

Moore M. 1982. Centers for Disease Control. Enteroviral disease in the United States, 1970-1979. J Infect Dis 146: $103-108$.

Muller AJ, Kaiser P, Dittmar KE, Weber TC, Haueter S, Endt K, Songhet P, Zellweger C, Kremer M, Fehling HJ, et al. 2012. Salmonella gut invasion involves TTSS-2-dependent epithelial traversal, basolateral exit, and uptake by epithelium-sampling lamina propria phagocytes. Cell Host Microbe 11: 19-32.

Mylonakis E, Paliou M, Hohmann EL, Calderwood SB, Wing EJ. 2002. Listeriosis during pregnancy: A case series and review of 222 cases. Medicine (Baltimore) 81: 260269.

Nagesh Babu G, Kumar A, Kalita J, Misra UK. 2008. Proinflammatory cytokine levels in the serum and cerebrospinal fluid of tuberculous meningitis patients. Neurosci Lett 436: $48-51$.

Nava P, Lopez S, Arias CF, Islas S, Gonzalez-Mariscal L. 2004 The rotavirus surface protein VP8 modulates the gate and fence function of tight junctions in epithelial cells. J Cell Sci 117: 5509-5519.

Niess JH, Brand S, Gu X, Landsman L, Jung S, McCormick BA, Vyas JM, Boes M, Ploegh HL, Fox JG, et al. 2005. CX3CR1-mediated dendritic cell access to the intestinal lumen and bacterial clearance. Science 307: 254-258.

Nikitas G, Deschamps C, Disson O, Niault T, Cossart P, Lecuit M. 2011. Transcytosis of Listeria monocytogenes across the intestinal barrier upon specific targeting of goblet cell accessible E-cadherin. J Exp Med 208: 22632277.

Nitta T, Hata M, Gotoh S, Seo Y, Sasaki H, Hashimoto N, Furuse M, Tsukita S. 2003. Size-selective loosening of the blood-brain barrier in claudin-5-deficient mice. J Cell Biol 161: 653-660.

Nizet V, Kim KS, Stins M, Jonas M, Chi EY, Nguyen D, Rubens CE. 1997. Invasion of brain microvascular endothelial cells by group B streptococci. Infect Immun 65: 5074-5081.

Orihuela CJ, Mahdavi J, Thornton J, Mann B, Wooldridge KG, Abouseada N, Oldfield NJ, Self T, Ala'Aldeen DA, Tuomanen EI. 2009. Laminin receptor initiates bacterial contact with the blood brain barrier in experimental meningitis models. J Clin Invest 119: 1638-1646.

Patrick D, Betts J, Frey EA, Prameya R, Dorovini-Zis K, Finlay BB. 1992. Haemophilus influenzae lipopolysaccharide disrupts confluent monolayers of bovine brain endothelial cells via a serum-dependent cytotoxic pathway. J Infect Dis 165: 865-872.

Pentecost M, Otto G, Theriot JA, Amieva MR. 2006. Listeria monocytogenes invades the epithelial junctions at sites of cell extrusion. PLoS Pathog 2: e3.

Pezzicoli A, Santi I, Lauer P, Rosini R, Rinaudo D, Grandi G, Telford JL, Soriani M. 2008. Pilus backbone contributes to group B Streptococcus paracellular translocation through epithelial cells. J Infect Dis 198: 890-898.

Pfister HW, Scheld WM. 1997. Brain injury in bacterial meningitis: Therapeutic implications. Curr Opin Neurol 10: $254-259$.

Pfister HW, Borasio GD, Dirnagl U, Bauer M, Einhaupl KM. 1992. Cerebrovascular complications of bacterial meningitis in adults. Neurology 42: 1497-1504.

Prasadarao NV, Wass CA, Huang SH, Kim KS. 1999a. Identification and characterization of a novel Ibe10 binding protein that contributes to Escherichia coli invasion of brain microvascular endothelial cells. Infect Immun 67: 1131-1138.

Prasadarao NV, Wass CA, Stins MF, Shimada H, Kim KS. 1999b. Outer membrane protein A-promoted actin condensation of brain microvascular endothelial cells is required for Escherichia coli invasion. Infect Immun 67: 5775-5783.

Prasadarao NV, Srivastava PK, Rudrabhatla RS, Kim KS, Huang SH, Sukumaran SK. 2003. Cloning and expression of the Escherichia coli K1 outer membrane protein A receptor, a gp96 homologue. Infect Immun 71: 16801688 .

Radin JN, Orihuela CJ, Murti G, Guglielmo C, Murray PJ, Tuomanen EI. 2005. $\beta$-Arrestin 1 participates in plateletactivating factor receptor-mediated endocytosis of Streptococcus pneumoniae. Infect Immun 73: 7827-7835.

Reijerkerk A, Kooij G, van der Pol SM, Khazen S, Dijkstra CD, de Vries HE. 2006. Diapedesis of monocytes is associated with MMP-mediated occludin disappearance in brain endothelial cells. FASEB J 20: 2550-2552.

Rescigno M. 2011. Dendritic cells in bacteria handling in the gut. J Leukoc Biol 90: 669-672.

Rescigno M, Di Sabatino A. 2009. Dendritic cells in intestinal homeostasis and disease. J Clin Invest 119: 2441 2450.

Rescigno M, Urbano M, Valzasina B, Francolini M, Rotta G, Bonasio R, Granucci F, Kraehenbuhl JP, Ricciardi-Castagnoli P. 2001. Dendritic cells express tight junction 


\section{K.S. Doran et al.}

proteins and penetrate gut epithelial monolayers to sample bacteria. Nat Immunol 2: 361-367.

Rieder G, Fischer W, Haas R. 2005. Interaction of Helicobacter pylori with host cells: Function of secreted and translocated molecules. Curr Opin Microbiol 8: 67-73.

Ring A, Weiser JN, Tuomanen EI. 1998. Pneumococcal trafficking across the blood-brain barrier. Molecular analysis of a novel bidirectional pathway. J Clin Invest 102: 347-360.

Robbins JR, Skrzypczynska KM, Zeldovich VB, Kapidzic M, Bakardjiev AI. 2010. Placental syncytiotrophoblast constitutes a major barrier to vertical transmission of Listeria monocytogenes. PLoS Pathog 6: e1000732.

Robbins JR, Zeldovich VB, Poukchanski A, Boothroyd JC Bakardjiev AI. 2012. Tissue barriers of the human placenta to infection with Toxoplasma gondii. Infect Immun 80: $418-428$.

Robertson SL, Smedley JG III, McClane BA. 2010. Identification of a claudin- 4 residue important for mediating the host cell binding and action of Clostridium perfringens enterotoxin. Infect Immun 78: 505-517.

Rubin LL, Staddon JM. 1999. The cell biology of the bloodbrain barrier. Annu Rev Neurosci 22: 11-28.

Rudini N, Dejana E. 2008. Adherens junctions. Curr Biol 18: R1080-1082.

Saadat I, Higashi H, Obuse C, Umeda M, Murata-Kamiya N, Saito Y, Lu H, Ohnishi N, Azuma T, Suzuki A, et al. 2007. Helicobacter pylori CagA targets PAR1/MARK kinase to disrupt epithelial cell polarity. Nature 447: 330-333.

Saez-Llorens X, Jafari HS, Severien C, Parras F, Olsen KD, Hansen EJ, Singer II, McCracken GH Jr. 1991. Enhanced attenuation of meningeal inflammation and brain edema by concomitant administration of anti-CD18 monoclonal antibodies and dexamethasone in experimental Haemophilus meningitis. J Clin Invest 88: 2003-2011.

Satosar A, Ramirez NC, Bartholomew D, Davis J, Nuovo GJ 2004. Histologic correlates of viral and bacterial infection of the placenta associated with severe morbidity and mortality in the newborn. Hum Pathol 35: 536-545.

Scheld WM, Koedel U, Nathan B, Pfister HW. 2002. Pathophysiology of bacterial meningitis: Mechanism(s) of neuronal injury. J Infect Dis 186: S225-233.

Scherf A, Pouvelle B, Buffet PA, Gysin J. 2001. Molecular mechanisms of Plasmodium falciparum placental adhesion. Cell Microbiol 3: 125-131.

Schubert-Unkmeir A, Sokolova O, Panzner U, Eigenthaler M, Frosch M. 2007. Gene expression pattern in human brain endothelial cells in response to Neisseria meningitidis. Infect Immun 75: 899-914.

Schubert-Unkmeir A, Konrad C, Slanina H, Czapek F, Hebling S, Frosch M. 2010. Neisseria meningitidis induces brain microvascular endothelial cell detachment from the matrix and cleavage of occludin: A role for MMP-8. PLoS Pathog 6: e1000874.

Schulze C, Firth JA. 1993. Immunohistochemical localization of adherens junction components in blood-brain barrier microvessels of the rat. J Cell Sci 104: 773-782.

Sharief MK, Ciardi M, Thompson EJ. 1992. Blood-brain barrier damage in patients with bacterial meningitis: Association with tumor necrosis factor- $\alpha$ but not interleukin-1 $\beta$. J Infect Dis 166: 350-358.
Sheen TR, Ebrahimi CM, Hiemstra IH, Barlow SB, Peschel A, Doran KS. 2010. Penetration of the blood-brain barrier by Staphylococcus aureus: Contribution of membrane-anchored lipoteichoic acid. J Mol Med 88: 633639.

Slanina H, Konig A, Hebling S, Hauck CR, Frosch M, Schubert-Unkmeir A. 2010. Entry of Neisseria meningitidis into mammalian cells requires the Src family protein tyrosine kinases. Infect Immun 78: 1905-1914.

Smith AL, Smith DH, Averill DR Jr, Marino J, Moxon ER. 1973. Production of Haemophilus influenzae b meningitis in infant rats by intraperitoneal inoculation. Infect Immun 8: 278-290.

Sokolova O, Heppel N, Jagerhuber R, Kim KS, Frosch M, Eigenthaler M, Schubert-Unkmeir A, Turner DP, Marietou AG, Johnston L, et al. 2004. Interaction of Neisseria meningitidis with human brain microvascular endothelial cells: Role of MAP- and tyrosine kinases in invasion and inflammatory cytokine release. Cell Microbiol 6: $1153-1166$

Sonoda N, Furuse M, Sasaki H, Yonemura S, Katahira J, Horiguchi Y, Tsukita S. 1999. Clostridium perfringens enterotoxin fragment removes specific claudins from tight junction strands: Evidence for direct involvement of claudins in tight junction barrier. J Cell Biol 147: 195204.

Soriani M, Santi I, Taddei A, Rappuoli R, Grandi G, Telford JL. 2006. Group B Streptococcus crosses human epithelial cells by a paracellular route. J Infect Dis 193: 241-250.

Sousa S, Lecuit M, Cossart P. 2005. Microbial strategies to target, cross or disrupt epithelia. Curr Opin Cell Biol 17: 489-498.

Stent G, Crowe SM. 1997. Effects of HIV-1 on the surface expression of LFA-1 on cultured monocytes. J Acquir Immune Defic Syndr Hum Retrovirol 15: 95-103.

Stins MF, Prasadarao NV, Ibric L, Wass CA, Luckett P, Kim KS. 1994. Binding characteristics of S fimbriated Escherichia coli to isolated brain microvascular endothelial cells. Am J Pathol 145: 1228-1236.

Sukumaran SK, Prasadarao NV. 2003. Escherichia coli K1 invasion increases human brain microvascular endothelial cell monolayer permeability by disassembling vascular-endothelial cadherins at tight junctions. J Infect Dis 188: $1295-1309$.

Swords WE, Ketterer MR, Shao J, Campbell CA, Weiser JN, Apicella MA. 2001. Binding of the non-typeable Haemophilus influenzae lipooligosaccharide to the PAF receptor initiates host cell signalling. Cell Microbiol 3: 525-536.

Tafazoli F, Zeng CQ, Estes MK, Magnusson KE, Svensson L. 2001. NSP4 enterotoxin of rotavirus induces paracellular leakage in polarized epithelial cells. J Virol 75: 15401546.

Tazi A, Disson O, Bellais S, Bouaboud A, Dmytruk N, Dramsi S, Mistou MY, Khun H, Mechler C, Tardieux I, et al. 2010. The surface protein HvgA mediates group B Streptococcus hypervirulence and meningeal tropism in neonates. J Exp Med 207: 2313-2322.

Temesvari P, Abraham CS, Speer CP, Kovacs J, Megyeri P. 1993. Escherichia coli 0111 B4 lipopolysaccharide given intracisternally induces blood-brain barrier opening during experimental neonatal meningitis in piglets. $P e-$ diatr Res 34: 182-186. 
Teng CH, Cai M, Shin S, Xie Y, Kim KJ, Khan NA, Di Cello F Kim KS. 2005. Escherichia coli K1 RS218 interacts with human brain microvascular endothelial cells via type 1 fimbria bacteria in the fimbriated state. Infect Immun 73: $2923-2931$.

Tobias L, Cordes DO, Schurig GG. 1993. Placental pathology of the pregnant mouse inoculated with Brucella abortus strain 2308. Vet Pathol 30: 119-129.

Tondury G, Smith DW. 1966. Fetal rubella pathology. J Pediatr 68: 867-879.

Tunkel AR, Scheld WM. 1995. Acute bacterial meningitis. Lancet 346: 1675-1680.

Tuomanen EI, Saukkonen K, Sande S, Cioffe C, Wright SD. 1989. Reduction of inflammation, tissue damage, and mortality in bacterial meningitis in rabbits treated with monoclonal antibodies against adhesion-promoting receptors of leukocytes. J Exp Med 170: 959-969.

Tyler JS, Boothroyd JC. 2011. The carboxyl terminus of Toxoplasma RON2 provides the crucial link between AMA1 and the host-associated invasion complex. PLoS Pathog 7: e1001282.

Uchiyama S, Carlin AF, Khosravi A, Weiman S, Banerjee A, Quach D, Hightower G, Mitchell TJ, Doran KS, Nizet V. 2009. The surface-anchored NanA protein promotes pneumococcal brain endothelial cell invasion. $J$ Exp Med 206: 1845-1852.

Unkmeir A, Latsch K, Dietrich G, Wintermeyer E, Schinke B, Schwender S, Kim KS, Eigenthaler M, Frosch M. 2002. Fibronectin mediates Opc-dependent internalization of Neisseria meningitidis in human brain microvascular endothelial cells. Mol Microbiol 46: 933-946.

Vadeboncoeur N, Segura M, Al-Numani D, Vanier G, Gottschalk M. 2003. Pro-inflammatory cytokine and chemokine release by human brain microvascular endothelial cells stimulated by Streptococcus suis serotype 2. FEMS Immunol Med Microbiol 35: 49-58.

van Sorge NM, Ebrahimi CM, McGillivray SM, Quach D, Sabet M, Guiney DG, Doran KS. 2008. Anthrax toxins inhibit neutrophil signaling pathways in brain endothelium and contribute to the pathogenesis of meningitis. PLoS ONE 3: e2964.

van Sorge NM, Quach D, Gurney MA, Sullam PM, Nizet V, Doran KS. 2009. The group B streptococcal serine-rich repeat 1 glycoprotein mediates penetration of the bloodbrain barrier. J Infect Dis 199: 1479-1487.

van Sorge NM, Zialcita PA, Browne SH, Quach D, Guiney DG, Doran KS. 2011. Penetration and activation of brain endothelium by Salmonella enterica serovar Typhimurium. J Infect Dis 203: 401-405.

Verma S, Lo Y, Chapagain M, Lum S, Kumar M, Gurjav U, Luo H, Nakatsuka A, Nerurkar VR. 2009. West Nile virus infection modulates human brain microvascular endothelial cells tight junction proteins and cell adhesion molecules: Transmigration across the in vitro blood-brain barrier. Virology 385: 425-433.
Virji M, Saunders JR, Sims G, Makepeace K, Maskell D, Ferguson DJ. 1993. Pilus-facilitated adherence of Neisseria meningitidis to human epithelial and endothelial cells: Modulation of adherence phenotype occurs concurrently with changes in primary amino acid sequence and the glycosylation status of pilin. Mol Microbiol 10: 10131028.

Voth DE, Ballard JD. 2005. Clostridium difficile toxins: Mechanism of action and role in disease. Clin Microbiol Rev 18: 247-263.

Waage A, Halstensen A, Shalaby R, Brandtzaeg P, Kierulf P, Espevik T. 1989. Local production of tumor necrosis factor $\alpha$, interleukin 1 , and interleukin 6 in meningococcal meningitis. Relation to the inflammatory response. J Exp Med 170: 1859-1867.

Watson KG, Holden DW. 2010. Dynamics of growth and dissemination of Salmonella in vivo. Cell Microbiol 12: 1389-1397.

Weksler BB, Subileau EA, Perriere N, Charneau P, Holloway K, Leveque M, Tricoire-Leignel H, Nicotra A, Bourdoulous S, Turowski P, et al. 2005. Blood-brain barrier-specific properties of a human adult brain endothelial cell line. FASEB J 19: 1872-1874.

Wickham ME, Brown NF, Provias J, Finlay BB, Coombes BK. 2007. Oral infection of mice with Salmonella enterica serovar Typhimurium causes meningitis and infection of the brain. BMC Infect Dis 7: 65 .

Wilson SL, Drevets DA. 1998. Listeria monocytogenes infection and activation of human brain microvascular endothelial cells. J Infect Dis 178: 1658-1666.

Winkler L, Gehring C, Wenzel A, Muller SL, Piehl C, Krause G, Blasig IE, Piontek J. 2009. Molecular determinants of the interaction between Clostridium perfringens enterotoxin fragments and claudin-3. J Biol Chem 284: 1886318872.

Wolburg H, Lippoldt A. 2002. Tight junctions of the bloodbrain barrier: Development, composition and regulation. Vascul Pharmacol 38: 323-337.

Wong AR, Pearson JS, Bright MD, Munera D, Robinson KS, Lee SF, Frankel G, Hartland EL. 2011. Enteropathogenic and enterohaemorrhagic Escherichia coli: Even more subversive elements. Mol Microbiol 80: 1420-1438.

Yoshida N, Tyler KM, Llewellyn MS. 2011. Invasion mechanisms among emerging food-borne protozoan parasites. Trends Parasitol 27: 459-466.

Zhang WG, Khan AN, Kim KJ, Stins M, Kim KS. 2002. Transforming growth factor- $\beta$ increases Escherichia coli $\mathrm{K} 1$ adherence, invasion, and transcytosis in human brain microvascular endothelial cells. Cell Tissue Res 309: 281-286.

Zysk G, Schneider-Wald BK, Hwang JH, Bejo L, Kim KS, Mitchell TJ, Hakenbeck R, Heinz HP. 2001. Pneumolysin is the main inducer of cytotoxicity to brain microvascular endothelial cells caused by Streptococcus pneumoniae. Infect Immun 69: 845-852. 


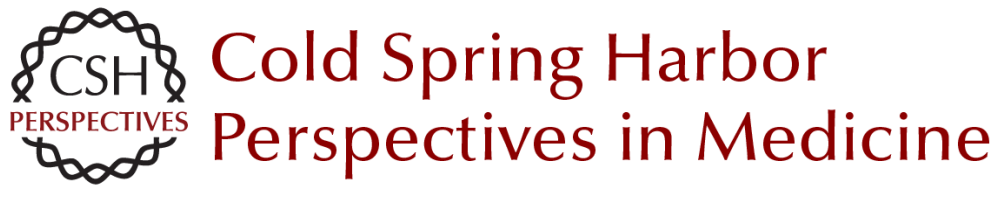

\section{Concepts and Mechanisms: Crossing Host Barriers}

Kelly S. Doran, Anirban Banerjee, Olivier Disson and Marc Lecuit

Cold Spring Harb Perspect Med 2013; doi: 10.1101/cshperspect.a010090

Subject Collection Bacterial Pathogenesis

Therapeutic and Prophylactic Applications of Bacteriophage Components in Modern Medicine Sankar Adhya, Carl R. Merril and Biswajit Biswas

Vaccines, Reverse Vaccinology, and Bacterial Pathogenesis Isabel Delany, Rino Rappuoli and Kate L. Seib

Helicobacter and Salmonella Persistent Infection Strategies

Denise M. Monack

Echoes of a Distant Past: The cag Pathogenicity Island of Helicobacter pylori

Nicola Pacchiani, Stefano Censini, Ludovico Buti, et al.

RNA-Mediated Regulation in Pathogenic Bacteria Isabelle Caldelari, Yanjie Chao, Pascale Romby, et al.

The Pneumococcus: Epidemiology, Microbiology, and Pathogenesis

Birgitta Henriques-Normark and Elaine I. Tuomanen

Pathogenesis of Meningococcemia Mathieu Coureuil, Olivier Join-Lambert, Hervé Lécuyer, et al.

Chlamydial Intracellular Survival Strategies Robert J. Bastidas, Cherilyn A. Elwell, Joanne N. Engel, et al.
Mechanisms and Biological Roles of

Contact-Dependent Growth Inhibition Systems

Christopher S. Hayes, Sanna Koskiniemi, Zachary

C. Ruhe, et al.

A Genome-Wide Perspective of Human Diversity and Its Implications in Infectious Disease Jérémy Manry and Lluis Quintana-Murci

Host Specificity of Bacterial Pathogens Andreas Bäumler and Ferric C. Fang

The Inside Story of Shigella Invasion of Intestinal Epithelial Cells

Nathalie Carayol and Guy Tran Van Nhieu

Bartonella and Brucella--Weapons and Strategies for Stealth Attack

Houchaima Ben-Tekaya, Jean-Pierre Gorvel and Christoph Dehio

Concepts and Mechanisms: Crossing Host

Barriers

Kelly S. Doran, Anirban Banerjee, Olivier Disson, et al.

Genome Dynamics in Legionella: The Basis of

Versatility and Adaptation to Intracellular

Replication

Laura Gomez-Valero and Carmen Buchrieser

Mechanisms of Francisella tularensis Intracellular

Pathogenesis

Jean Celli and Thomas C. Zahrt

For additional articles in this collection, see http://perspectivesinmedicine.cshlp.org/cgi/collection/ 